IHS Working Paper 19

August 2020

\title{
Selection into Leadership and Dishonest Behavior of Leaders: A Gender Experiment
}

Kerstin Grosch Stephan Müller Holger A. Rau Lilia Zhurakhovska 


\section{Author(s)}

Kerstin Grosch, Stephan Müller, Holger A. Rau, Lilia Zhurakhovska

\section{Editor(s)}

Robert M. Kunst

Title

Selection into Leadership and Dishonest Behavior of Leaders: A Gender Experiment

Institut für Höhere Studien - Institute for Advanced Studies (IHS)

Josefstädter Straße 39, A-1080 Wien

$\mathrm{T}+431$ 59991-0

$\mathrm{F}+43159991-555$

www.ihs.ac.at

ZVR: 066207973

\section{Funder(s)}

University of Goettingen, University of Duisburg-Essen

\section{License}

„Selection into Leadership and Dishonest Behavior of Leaders: A Gender Experiment" by Kerstin Grosch, Stephan Müller, Holger A. Rau, Lilia Zhurakhovska is licensed under the Creative Commons: Attribution 4.0 License (http://creativecommons.org/licenses/by/4.0/)

All contents are without guarantee. Any liability of the contributors of the IHS from the content of this work is excluded.

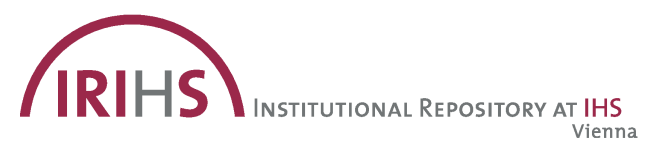

All IHS Working Papers are available online:

https://irihs.ihs.ac.at/view/ihs_series/ser=5Fihswps.html

This paper is available for download without charge at: https://irihs.ins.ac.at/id/eprint/5413/ 


\title{
Selection into Leadership and Dishonest Behavior of Leaders: A Gender Experiment*
}

\author{
Kerstin Grosch ${ }^{\dagger 1}$, Stephan Müller ${ }^{\ddagger 2}$, Holger A. Rau ${ }^{\S 2}$, and Lilia Zhurakhovska ${ }^{\llbracket 3}$ \\ ${ }^{1}$ Institute for Advanced Studies \\ ${ }^{2}$ University of Göttingen \\ ${ }^{3}$ University of Duisburg-Essen
}

August 2020

\begin{abstract}
Leaders often have to weigh ethical against monetary consequences. Such situations may evoke psychological costs from being dishonest and dismissing higher monetary benefits for others. In a within-subjects experiment, we analyze such a dilemma. We first measure individual dishonest behavior when subjects report the outcome of a die roll, which determines their payoffs. Subsequently, they act as leaders and report payoffs for a group including themselves. In our main treatment, subjects can apply for leadership, whereas in the control treatment, we assign leadership randomly. Results reveal that women behave more dishonestly as leaders while men behave similarly in both the individual and the group decision. For female leaders, we find that sorting into leadership is not related to individual honesty preferences. In the control we find that female leaders do not increase dishonesty. A followup study reveals that female leaders become more dishonest after assuming leadership, as they align dishonest behavior with their belief on group members' honesty preferences.
\end{abstract}

JEL Classification numbers: C91, H26, J16

Keywords: leadership, decision for others, lab experiment, gender differences, dishonesty

\footnotetext{
${ }^{*}$ We are grateful to Martin Kocher and Marie Claire Villeval for helpful comments. We would also like to thank participants in audiences at the University of Duisburg-Essen, at the Gender Economics and Workplace conference in Nürnberg, and the VCEE in Vienna. Or thanks also go to Volker Benndorf for programming the matching algorithm of study 2. Financial support is acknowledged to the University of Göttingen.

${ }^{\dagger}$ Josefstaedter Str. 39, 1080 Vienna (Austria), E-mail: grosch@ihs.ac.at

${ }^{\ddagger}$ Platz der Göttinger Sieben 3, 37073 Göttingen (Germany), E-mail: stephan.mueller@wiwi.uni-goettingen.de

${ }^{\S}$ Corresponding author, Platz der Göttinger Sieben 3, 37073 Göttingen (Germany), E-mail: holger.rau@unigoettingen.de

${ }^{\circledR}$ Lotharstr. 65, 47057 Duisburg (Germany),E-mail: lilia.zhurakhovska@uni-due.de
} 


\section{Introduction}

Leadership behavior and selection into leadership positions play a key role for the performance of teams in firms, sport teams, or political parties (Peterson et al., 2012; Lorinkova et al., 2013; Bandiera et al., 2020). Although evidence suggests that a higher share of women is beneficial for a company's performance, women are still largely underrepresented in leadership positions (Flabbi et al., 2019; Zenger and Folkman, 2019). Besides historical gender-role attitudes (Alesina et al., 2013), gender differences in preferences (Croson and Gneezy, 2009) are a potential explanation for why women partly sort out. That is, they lack risk tolerance, confidence, or competitive preferences, as compared to men (e.g., Barber and Odean, 2001; Eckel and Grossman, 2002; Niederle and Vesterlund, 2007; Ertac and Gurdal, 2012; Alan and Ertac, 2019; Alan et al., 2020). Moreover, women have been shown to be less dishonest than men in selfish-black-lie situations (e.g., Dreber and Johannesson, 2008; Grosch and Rau, 2017). Since leadership decisions may require that they bend rules at times when there are social, monetary, or other incentives in place, differences in dishonest behavior may be another piece of the puzzle explaining gender differences in leadership sorting and behavior.

There are two key motivations for behaving dishonestly as a leader. First, leaders benefit personally since they are typically compensated and promoted based on their performance. Thus, leaders have an incentive to misreport outcomes, particularly to the entities relevant for their performance evaluation (Burns and Kedia, 2006). Second, leaders' decisions impact the payoffs of different stakeholders, e.g., shareholders in the case of managers or a politician's staff members (Berman et al., 1999). Since a leader is, at least partially, evaluated based on the satisfaction of the stakeholders' needs and aspirations, his or her decisions are shaped by the beliefs about stakeholders' preferences. Moreover, the payoff externalities of leadership decisions highlight the potential role of social preferences or norms for decision-making.

In this paper, we study how people's dishonest behavior is affected by leadership, i.e., when they decide as leaders who are assuming responsibility for a group. Moreover, we investigate whether the decision to become a leader is motivated by individual honesty preferences. Analyzing gender differences in the willingness to become a leader contributes to a better understanding of selection effects into leadership roles. In this respect, we can analyze whether the gender gap in executive positions may be related to gender differences in dishonesty.

To study dishonest behavior, we conducted an experiment where subjects repeatedly report outcomes of a die roll that determines payoffs. This method is known as the die-rolling game by Fischbacher and Föllmi-Heusi (2013). Here, participants roll a die and receive a payoff that increases in the reported outcome. Although the experiment is stylized, it encompasses characteristics which may model dishonest behavior in business situations. ${ }^{1}$ For instance, the reporting set-up resembles situations in which managers know the real outcome and may intentionally misreport to increase company returns (e.g., Burns and Kedia, 2006; Bollen and Pool,

\footnotetext{
${ }^{1}$ See Abeler et al. (2019) for a meta-study analysis on dishonest behavior.
} 
2009), the sale figures of teams (Church et al., 2012), or wrong figures to evade taxes (Joulfaian, 2000). All these dishonest actions have in common that there is a low chance of getting caught and punished. The real-life implications of the die-rolling game has been demonstrated in the fields of corrupt behavior (Hanna and Wang, 2017), free riding in public transportation (Potters and Stoop, 2016), and refraining from reporting over-payments (Dai et al., 2018).

In our within-subjects experiment, participants report the outcome of a die roll twice. First, subjects only report for themselves, which serves as a proxy for individual honesty preferences. Subsequently, we measure dishonest behavior when assuming responsibility for a group. That is, they report the outcome of a die roll as group leaders, which determines their payoff and the payoff of two group members. Before they make this decision, we analyze subjects' willingness to take up leadership by asking them whether they want to become a leader or not. They know that if more than one person says "yes," a random draw will select one of the applicants. ${ }^{2}$ Measuring leadership preferences allows us two things. First, we can study whether individual honesty preferences affect the decision to become leaders. Second, we can analyze whether the willingness to take up leadership affects dishonest behavior for groups. To isolate the effects of endogenous leadership, we ran a control treatment without the possibility to apply for leadership.

The results demonstrate that women behave less dishonestly than men when deciding on individual payoffs. This gender difference vanishes when subjects make their second reporting decision in the role of a group leader. This can be explained by women increasing dishonest behavior as leaders, particularly those who have a willingness to act as a leader. We find that men with a preference for dishonesty self-select into leadership and show similar misreporting behavior in the group domain as in the individual domain. By contrast, women's willingness to take over leadership is not related to their individual honesty preferences. Our control treatment highlights that women only increase dishonest behavior for groups when they could apply for leadership, but not when there was an external appointment. The results demonstrate that women's increase in dishonesty is not driven by the group context per se. It is spurred by a combination of the explicit decision to act as a leader and to decide on behalf of others.

To further investigate the underlying mechanisms of women increasing dishonest behavior as a leader of a group, we conducted a second study that is similar to the first study. Here, we additionally elicit leaders' beliefs on the honesty preferences of group members. We interpret this measure as the leader's perceived group norm. The study also controls for subjects' social value orientation to account for a possible relation between prosociality and misreporting for groups. Perceived norms seem to be the key driver for female leaders to increase misreporting for groups; particularly for women who applied for leadership. By contrast, for women who did not apply for leadership, social value orientation explains their preference for being dishonest to support the group.

Our study sheds light on the scarce experimental evidence on gender differences in leadership

\footnotetext{
${ }^{2}$ If no person applies, one of all three group members is randomly selected.
} 
behavior. We highlight that women alter their behavior when they act as leaders and applied for a position while men do not. Moreover, we contribute to a better understanding of the lack of female leaders. There are many explanations for why women are underrepresented in leadership positions. Some of these are worse overall evaluations of women with similar performance than men (Boring, 2017; Mengel et al., 2019; Özgümüs et al., 2020), ${ }^{3}$ fewer promotions of highqualified women compared to men (Bohnet et al., 2016), and less appreciation of female leaders by employees (Grossman et al., 2019). Our experiment adds to this literature by analyzing the relation of honesty preferences on the decision to become a leader. Our data analysis suggests that women's general aversion to behaving dishonestly cannot explain their hesitance to apply and take up leadership positions. Moreover, we provide evidence of whether men and women show behavioral changes when promoted to leadership. This may help to better anticipate the impact of personnel decisions on management success. The behavioral change of women's honesty when promoted to leaders, suggests for women's quota in executive positions that it may not lead to more ethical leaders.

\section{Study 1: Experimental Design}

In this section, we describe the design of our within-subjects experiment. At the beginning of the experiment, we elicit subjects' preferences (risk preferences, inequality aversion, competition preferences, and ambiguity preferences) in separate parts with incentives to account for individual heterogeneity. ${ }^{4}$ They are told that at the end of the session, the computer would randomly select one of the parts for payoff. Afterward, we apply modifications of the die-rolling game introduced by Fischbacher and Föllmi-Heusi (2013) to measure dishonest behavior when deciding onx individual payoffs ("individual preferences for honesty") and group payoffs ("preferences for honesty in groups"). For each part, subjects receive new instructions and we inform them step by step about the subsequent part. In the following, we describe briefly the preference elicitation parts (detailed instructions of the elicitation parts can be found in Appendix B). Then, we present the two die-rolling games. At the end of each session, we apply a questionnaire with socio-demographic questions.

\subsection{Elicitation of Individual Preferences}

In part one, we measure individual risk preferences based on the method by Eckel and Grossman (2002). Subjects choose one out of six lotteries. The risky nature of the chosen lottery determines subjects' risk tolerance. Afterward, we measure subjects' inequality aversion parameters of the Fehr and Schmidt (1999) model with the method of Blanco et al. (2011). That is, in part two, we elicit subjects' aversion to advantageous inequality $(\beta)$ and, in part three, we measure their

\footnotetext{
${ }^{3}$ Card et al. (2020) study the role of gender in the evaluation of economic papers. Although, they find that female authors even are more often cited than male authors, their papers are not more often accepted.

${ }^{4}$ We also use these data in another research project on elicitation methods of preferences (Grosch et al., 2020).
} 
aversion to disadvantageous inequality $(\alpha)$. Here, subjects are shown choice sets with varying money allocations between themselves and another participant. Their choices in these tasks determine their inequality-aversion parameters. Competitive preferences are measured with the design of Niederle and Vesterlund (2007) in parts four to six. In part four, subjects work in a real-effort task and are paid by a piece rate whereas in part five the remuneration of the task is based on the outcome of a tournament. In part six, subjects have to decide whether to compete in a tournament or to work individually on the task and be paid by piece rate. The decision classifies subjects as competitive or not. In part seven, we measure ambiguity preferences applying a multiple-price-list design by Gneezy et al. (2015). Subjects are presented with pairs of risky gambles with constant payoffs and ambiguous gambles with increasing payoffs. Subjects who switch earlier (later) from the risky to the ambiguous gamble are classified by lower (higher) ambiguity preferences.

\subsection{Individual Preferences for Honesty}

To get an idea on individual honesty preferences, in this part we measure subjects' general misreporting as a benchmark. This is an essential part of our within-subjects experiment as it enables us to compare honesty preferences when subjects decide for themselves to the situation, where they can misreport for groups. To measure honesty preferences, we implement a version of the method by Fischbacher and Föllmi-Heusi (2013). Here, subjects have to report the outcome of a die-roll. To have control over individual misreporting behavior, we apply a computerized version of the die-rolling game that records the real die outcome. This approach is similar to Kocher et al. (2017). Here, subjects cannot disguise their lies and, therefore, we expect subjects to be less dishonest than in the original die-rolling game (Kajackaite and Gneezy, 2017). To demonstrate to subjects that the die is fair, they can repeatedly press a button for 20 seconds that randomly shows one side of a six-sided die whenever they press the button. At the end of the 20 seconds, subjects are informed that they should press the button one more time and report the outcome of the actual die roll. They know that the report determines their payment in this task. The payment of each report corresponds to the reported number times three. For instance, a one yields $€ 3$, a two yields $€ 6$, .., a five yields $€ 15$. The only exception is the number six that yields no payment so as to mitigate the risk of introducing a focal point (Fischbacher and Föllmi-Heusi, 2013).

\subsection{Preferences for Honesty in Groups}

In this part, we play a die-rolling game similar to the previous one. That is, subjects again roll a six-sided die and report the outcome. We apply the same payoff structure as in the previous part (e.g., reporting a four yields a payoff of $€ 12$ ). This time, we refrain from the 20 -second trial phase. The crucial difference is that subjects learn that they have been randomly matched in groups of three. They are told that the payoff of each group member is determined by the 
report made by a group leader. It is made clear that each of the other group members receives the same payoff as the one reported by the leader. We do not use the word "leader" in the instructions. Instead, we call the person who determines the group payoff: "Person A." Before subjects roll the die, they can choose whether they want to be in the role of "person A" (leader) or not. When only one person states a willingness to become the leader, she becomes the leader. When more than one person says "yes," a random draw selects one of the persons who applied for leadership. When no one applies, the random draw selects one person among the three group members. The choice mechanism enables us to relate the subjects' individual honesty preferences to their willingness to act as a leader. Moreover, we can analyze whether a subject's choice to assume responsibility has an effect on dishonest behavior when reporting group payoffs.

After subjects decide whether they want to act as a leader or not, we elicit their beliefs about how many of the other group members wanted to become the leader. Subjects receive $€ 1$ for a correct guess. In a next step, we apply the strategy method (Selten, 1967) to measure subjects' misreporting behavior when deciding for the group payoffs. Here, all subjects are told to roll the die once and report the payoff when they become a person A (leader). They know that this decision only becomes relevant if they are selected as the leader. That procedure allows us to compare the honesty preferences of all subjects, independent of whether they want to become leaders or not. Subjects are told the anonymous id (subject 1, 2, or 3 ) of the selected leader and they are informed of the report made by this subject at the end of the experiment. However, they are not informed of the real die outcome of this subject. We illustrate the sequence of actions in Figure 1.

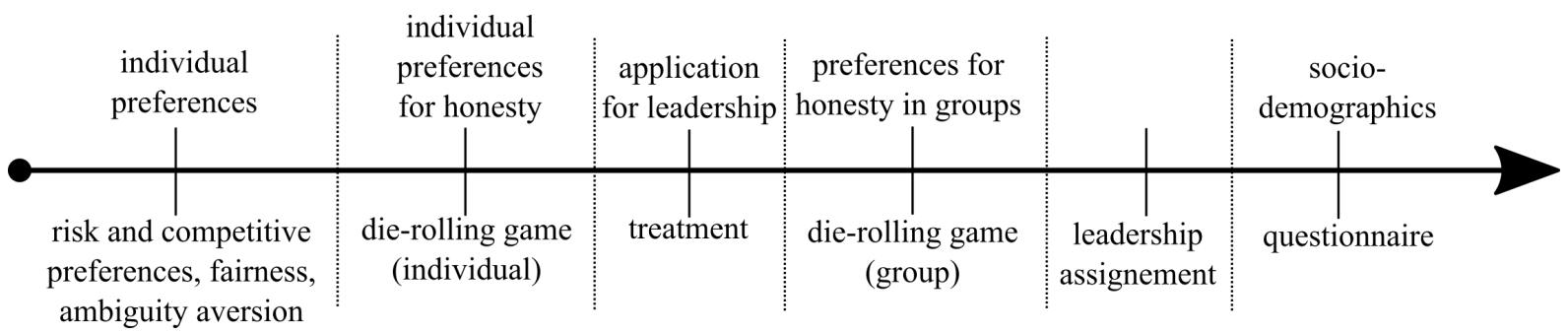

Figure 1: sequence of actions

Our experimental design models the hierarchical decisions of leaders. That is, subjects report in the role of leaders in a non-strategic situation the payoffs for the group. In contrast, Kocher et al. (2017) also analyze honesty in decisions for groups, but in their experiment decision-making is strategic, as group payoffs increase when group members coordinate. That is, subjects only earn a positive amount if they report the same die outcome as the other group members. ${ }^{5}$ Another difference is that our subjects decide independently of others, whereas subjects in Kocher et al. (2017) meet in a chat before they make their reporting decisions. We deliberately refrain from a strategic group context to avoid confounds for answering our research question

\footnotetext{
${ }^{5}$ In a control treatment, they also analyze simultaneous group decisions of reporting individual payoffs when subjects do not have to achieve commonality.
} 
on leaders' decision to report payoffs on behalf of their teams.

To disentangle the effects of the endogenous leadership on dishonest behavior, we run a control treatment with a random external appointment of leaders without group members having the possibility to apply. To account for the possibility that subjects in our main treatment may hold different beliefs on the likelihood of ending up as a leader, we apply different probabilities of becoming a leader in the exogenous treatment. The probabilities vary between one third, i.e., we tell all three group members that their probability of becoming a leader is one third, and a half, i.e., we tell one group member that she cannot become a leader for sure, while the other two group-members are told that the probability of becoming a leader is one half. ${ }^{6}$ With the exception of the exogenous leader choice, where subjects are told the probabilities of becoming a leader, everything else is similar in the control treatment as compared to the main treatment.

\subsection{Procedure}

The experiment was conducted at a German university and it was programmed with the software z-Tree (Fischbacher, 2007). Subjects were recruited with the subject-pool software ORSEE (Greiner, 2015). In total, 282 subjects participated in the experiments (144 in the main treatment; 138 in the control treatment). After subjects made their decisions, we ran a questionnaire to verbally elicit their preferences. This is part of another project on the relation of nonincentivized and incentivized preferences (Grosch et al., 2020). To control for order effects we conducted some sessions with the questionnaire at the beginning. At the very end of the experiment, we asked for subjects' socio-demographics. Participants were from various disciplines with a mean age of 23.60. In our sample we find that $50.4 \%$ of the subjects were female. Sessions lasted approximately 70 minutes. Subjects were paid in cash at the end of the experiment and earned an average of $€ 10.81$, including a show-up fee of $€ 5$. In the following, we start reporting the hypotheses and results of our main study (study 1).

\section{Study 1: Hypotheses}

In our analysis of honesty preferences we focus on the cases when subjects misreport payoffs. Therefore, we will use the term "dishonest behavior." The experimental literature on gender differences in individual misreporting behavior finds predominantly that men behave more dishonestly than women for selfish black lies, i.e., when being dishonest benefits oneself and harms another person/third party in the lab (Dreber and Johannesson, 2008; Houser et al., 2012; Conrads et al., 2014; Grosch and Rau, 2017) and in the field (Azar et al., 2013; Bucciol et al., 2013). This derives our first hypothesis on individual reporting behavior.

\footnotetext{
${ }^{6}$ We do not have groups in which only one group member could become the leader for sure as this is a very rare case in the endogenous treatment. This only applies for five of 144 cases.
} 


\section{Hypothesis 1:}

Men behave significantly more dishonestly than women when deciding for themselves.

Misreporting for the group generates a benefit for the team members and can therefore be seen as a Pareto improvement over telling the truth. Thus, subjects may receive an extra utility from dishonest behavior for the group than when deciding for themselves. In line with that, Gino et al. (2013) demonstrate that the more other people benefit from misreporting, the more people are willing to be dishonest. Hence, we expect that subjects are more likely to misreport for groups as compared to deciding for individual payoffs.

Women have been found, on average, to be more prosocial than men (e.g., Eckel and Grossman, 1998; Andreoni and Vesterlund, 2001; Croson and Gneezy, 2009; Rand et al., 2016). They are also expected to demonstrate higher prosociality at work compared to men (Brañas-Garza et al., 2018). When they do not follow this stereotypical expectation, they are evaluated more negatively than men with similar prosocial behavior (Heilman and Chen, 2005). Deciding to be dishonest for the group could be perceived as an act of being prosocial. In this case, there are two reasons why women may show a more pronounced increase of dishonest behavior for the group than men. First, they are expected to misreport when making decisions concerning others' payoffs and, second, they have more pronounced prosocial preferences than men.

\section{Hypothesis 2:}

(a) Subjects increase dishonest behavior when reporting payoffs for a group compared to reporting payoffs for themselves only.

(b) The increase in dishonest behavior for a group is more pronounced for women than for men.

People select into leadership positions based on characteristics such as risk preferences, overconfidence, or competitive preferences depending on the requirements of the leadership position (e.g., Barber and Odean, 2001; Eckel and Grossman, 2002; Niederle and Vesterlund, 2007; Ertac and Gurdal, 2012). For example, if a leadership position requires risky decisions to be made on behalf of a group, risk-loving people rather than risk-averse ones self-select into the leadership position (Ertac and Gurdal, 2012). Our setting resembles a decision context with potential gains from misreporting. Therefore, we expect that subjects' individual honesty preferences determine self-selection into the leadership role.

\section{Hypothesis 3:}

Subjects who behave dishonestly for themselves are more likely to apply for the leadership position.

In our design, when subjects state that they want to become a leader, they deliberately express their willingness to assume responsibility. The literature on endogenous institutions

emphasizes that subjects are more willing to stick to a certain behavior after they have deliber- 
ately voted for institutions. More precisely, subjects contribute more in public-good games after they have voted for a punishment institution that intends to prevent free riding (Kosfeld et al., 2009; Sutter et al., 2010). Moreover, there is evidence that leaders who volunteered as leaders contribute more to a public good than leaders who are exogenously appointed (Haigner and Wakolbinger, 2010; Rivas and Sutter, 2011). Based on this literature, we expect in our set-up that leaders who volunteered to become a leader are more willing to misreport for the group than subjects who did not apply for leadership. There may be subjects who behave honestly in individual decisions. It is possible that these subjects may behave similarly in the group domain. However, we do not believe that being an honest person motivates subjects to become a leader in general. When an honest subject does not become a leader and another leader behaves dishonestly, the subject would not be responsible for this decision. In contrast, there are strong monetary incentives for becoming a leader and to misreport in the group domain for dishonest subjects.

\section{Hypothesis 4:}

The increase in misreporting for groups is driven by dishonest subjects who applied for leadership.

\section{Study 1: Results}

In this section, we present our main results on dishonest behavior when subjects only reported individual payoffs and when they reported group payoffs. We start with our main results on endogenous leadership decisions. When applying non-parametric tests, we always report twosided p-values throughout.

\subsection{Main results}

Figure 2 focuses on subjects' misreporting behavior in our main treatment, where subjects can apply for leadership (endogenous leadership). We count all cases as "profitable dishonest reports" when subjects increased their payoffs by misreporting the real outcome of the die-roll. Then, the dummy variable "dishonest behavior" becomes one. Otherwise, this dummy variable is zero. ${ }^{7}$ This encompasses die outcomes between one and four, where subjects inflated their statements by reporting higher numbers between two and five, and when subjects rolled a six and reported a lower number (between one and five).

We show the reporting decisions of individual payoffs using white bars and the reporting decisions of group payoffs with black bars in Figure 2. The diagram conditions on men (left panel) and women (right panel). When reporting individual payoffs, our data confirm commonly found gender differences in dishonesty (e.g., Conrads et al., 2014; Grosch and Rau, 2017; Kocher et al.,

\footnotetext{
${ }^{7}$ The dummy variable is set to " 0 " when subjects reported the real outcome, or when they reported an outcome that was to their disadvantage. However, we do not observe the latter case in study 1.
} 


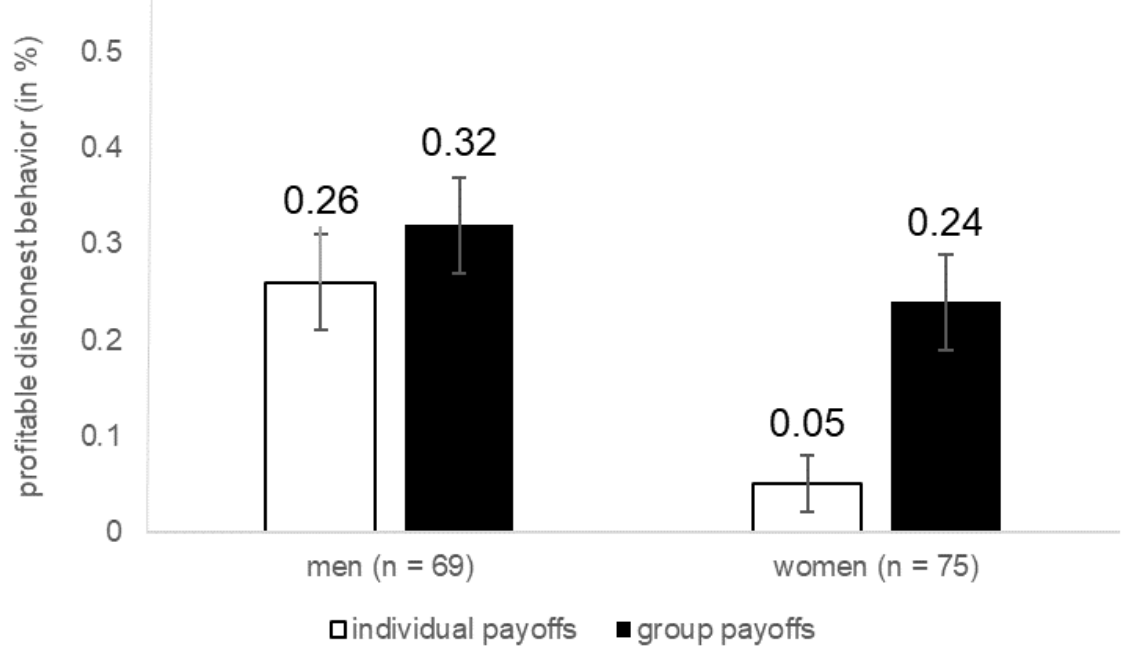

Figure 2: Percentage of profitable dishonest reports in endogenous leadership. White (black) bars present the reports for individual payoffs (group payoffs). Standard error bars included.

2017). That is, men are (26\%) five times more frequently dishonest than women (5\%) (Fisher's exact test, $p=0.001$ ).

We turn to our first research question and analyze the misreporting of the group leaders. It can be seen that the gender difference in dishonesty disappears when subjects report group payoffs (Fisher's exact test, $p=0.353$ ). In the group domain, women significantly increase dishonest behavior by more than four times from $5 \%$ to $24 \%$ (Wilcoxon matched-pairs test, $p<0.001$ ). By contrast, men show the same behavior in both contexts (individual payoffs: 26\%; group payoffs: $32 \%$ ) (Wilcoxon matched-pairs test, $p=0.346$ ). In general, we find that subjects behave more dishonestly when reporting group payoffs (28\%) than individual payoffs (15\%) (Wilcoxon matched-pairs test, $p=0.002)$. This is in line with the results from Kocher et al. (2017).

Table 1 demonstrates that our results are confirmed by random effects Probit regressions on the likelihood of behaving dishonestly.

Model (1) includes a gender dummy (female), which is positive for women and group payoff, a dummy which is positive when subjects make decisions affecting group payoffs. In model (2) we interact female and group payoff. In model (3) we include control variables for risk preferences, competition preferences, fairness (alpha and beta of the Fehr and Schmidt, 1999, model), ambiguity preferences, age, and whether subjects study economics. ${ }^{8}$ Each subject makes two reporting decisions $(\mathrm{n}=288)$. The regressions are clustered at the subject level $(\mathrm{n}=144)$. We report average marginal effects (see Table 5 in Appendix A for the corresponding Probit model).

In model (1), we find that female is highly significant with a negative sign. Thus, women

\footnotetext{
${ }^{8}$ As we elicited our preference measures with two different orders, we also included a dummy variable controlling for the order.
} 
Table 1: Random effects Probit regressions on dishonest behavior in endogenous leadership.

\begin{tabular}{lccc}
\hline \hline & \multicolumn{3}{c}{ dishonest behavior } \\
& $(1)$ & $(2)$ & $(3)$ \\
female & $0.140^{* * *}$ & $-0.266^{* * *}$ & $-0.183^{* *}$ \\
& $(0.052)$ & $(0.076)$ & $(0.078)$ \\
group payoff & $0.126^{* * *}$ & 0.046 & 0.047 \\
& $(0.039)$ & $(0.048)$ & $(0.050)$ \\
female $\times$ group payoff & & $0.202^{* *}$ & $0.200^{* *}$ \\
& & $(0.082)$ & $(0.083)$ \\
& & & \\
\hline controls ${ }^{a}$ & & no & yes \\
obs. & 288 & 288 & 288 \\
groups & 144 & 144 & 144 \\
\hline \multicolumn{4}{c}{ Standard errors in parentheses } \\
\hline \hline
\end{tabular}

Note: The regressions are clustered on the subject level $(\mathrm{n}=$ 144) and report average marginal effects.

${ }^{a}$ Controls: Risk preferences, competition preferences, fairness, ambiguity preferences, age, whether subjects study economics, and an order dummy.

generally behave less dishonestly than men. We therefore confirm Hypothesis 1. Moreover, group payoff is highly significant, i.e., subjects increase their dishonest behavior when being responsible for the payoffs of group members. Thus, we support Hypothesis 2a. Model (2) highlights that the increase in dishonest behavior for groups is entirely driven by women. When controlling for the interaction effect of female $\times$ group payoff, the coefficient of group payoff becomes insignificant. At the same time, the interaction is significant and positive. Thus, the interaction effect offsets the negative coefficient of female which confirms the absence of gender differences when deciding for the group. Model (3) shows that the finding is robust to the inclusion of control variables. ${ }^{9}$ The findings of models (2) and (3) confirm Hypothesis $2 \mathrm{~b}$. We summarize our findings.

\section{Result 1: Dishonest Behavior for Individual and Group Payoffs}

(a) Women behave less dishonestly than men when reporting individual payoffs.

(b) Women behave as dishonestly as men when acting as leaders.

\footnotetext{
${ }^{9}$ We find positive significant effects for risk tolerance and subjects studying economics. The order dummy is insignificant.
} 


\subsection{The Impact of Endogenous Leadership}

In this section, we test Hypothesis 3 and 4 to better understand the influencing factors of dishonest behavior for groups. For this, we focus on the impact of endogenous leadership. In our endogenous leadership treatment, subjects can actively apply to become a leader and saying "yes" increases the chance of ending up as a leader. Thus, this statement may work as a selection device. This would imply that subjects who state that they want leadership might systematically differ in their preferences from subjects who opted against it.

This idea follows our second research question and Hypothesis 3, which expects that individual honesty preferences are a predictor for the willingness to become a leader. Interestingly, it turns out that an insignificantly smaller share of women (71\%) than men (80\%) (Fisher's exact test, $p=0.250$ ) apply for leadership. Since women generally behave less dishonestly for themselves, the rather high share of women suggests that women may have other reasons to apply for leadership than honesty preferences.

To test Hypothesis 3 more thoroughly, we run Probit regressions (Table 2), analyzing the determinants of subjects' willingness to become a leader.

Table 2: Probit regressions on wanted leadership and dishonesty for groups (endog. leadership).

\begin{tabular}{|c|c|c|c|c|}
\hline & \multicolumn{2}{|c|}{ wanted leadership } & \multicolumn{2}{|c|}{ dishonesty for groups } \\
\hline & (1) & $(2)$ & (3) & (4) \\
\hline female & $\begin{array}{c}-0.057 \\
(0.073)\end{array}$ & $\begin{array}{c}-0.048 \\
(0.076)\end{array}$ & $\begin{array}{c}-0.061 \\
(0.073)\end{array}$ & $\begin{array}{c}0.049 \\
(0.078)\end{array}$ \\
\hline wanted leadership & & & $\begin{array}{c}0.196^{* *} \\
(0.091)\end{array}$ & $\begin{array}{c}0.186^{* *} \\
(0.087)\end{array}$ \\
\hline misreported for themselves & $\begin{array}{l}0.211^{*} \\
(0.122)\end{array}$ & $\begin{array}{c}0.329^{* *} \\
(0.159)\end{array}$ & & \\
\hline female $\times$ misreported for themselves & & $\begin{array}{l}-0.306 \\
(0.266)\end{array}$ & & \\
\hline controls $^{a}$ & no & yes & no & yes \\
\hline obs. & 144 & 144 & 144 & 144 \\
\hline $\begin{array}{l}\text { Standard erl } \\
* * * \mathrm{p}<0.01\end{array}$ & $\begin{array}{l}\text { ors in } \mathrm{pa} \\
* \mathrm{p}<0.0\end{array}$ & $\begin{array}{l}\text { ntheses } \\
* \mathrm{p}<0.1\end{array}$ & & \\
\hline
\end{tabular}

Note: The regressions report average marginal effects.

${ }^{a}$ Controls: Risk preferences, competition preferences, fairness, ambiguity preferences, age, whether subjects study economics, and an order dummy.

In models (1)-(2), we test whether subjects who want to become leaders differ in their socioeconomics, which may be proxies for preferences influencing misreporting for the group. That is, we can test whether individual honesty preferences predict the decision to become a leader. Therefore, we include a dummy (misreported for themselves) that is positive when subjects 
behaved dishonestly when deciding on individual payoffs and zero otherwise. We also control for subjects' gender (female) and the interaction effect of gender and individual misreporting (female $\times$ misreported for themselves). Model (2) includes the same set of controls as before. The models report average marginal effects (see Table 6 in Appendix A for the corresponding Probit model).

We find that the coefficient of misreported for themselves is significant, i.e., subjects who behave dishonestly at the individual level are more likely to become leaders. Female is not significant which confirms our finding of no gender differences in the willingness to become a leader. A closer look at model (2) reveals that the positive effect of honesty preferences is entirely driven by men. That is, misreported for themselves is only significant for men but not for women (Wald test, $p=0.915$ ). Thus, selection effects are obviously only in place for men but not for women, which supports Hypothesis 3 only for male leaders.

We turn to Hypothesis 4 to shed more light on the effects of endogenous leadership. We test whether subjects' deliberate decision to act as the leader may impact their behavior when reporting the payoffs of groups. Models (3)-(4) present this analysis and focus on dishonesty for groups. The models include a dummy variable (wanted leadership) that is positive when subjects applied for leadership. The models use a gender dummy and the same controls as in model (2). We find that subjects who applied for leadership are more likely to behave dishonestly when deciding for group payoffs. This is demonstrated by the positive and significant coefficient of wanted leadership. Model (4) highlights that among subjects who wanted to become leaders, the probability of a dishonest report is higher by 19 percentage points. ${ }^{10}$ Thus, we support Hypothesis 4. Wilcoxon matched-pairs tests show that the increase in dishonest behavior is driven by women who applied for leadership. They significantly behave more dishonestly for groups as compared to when they are deciding for themselves $(p<0.001)$. By contrast, this is not the case for men who want to become leaders $(p=0.607)$. We summarize our findings.

\section{Result 2: Determinants of Leadership and Consequences on Dishonesty in Groups}

(a) Men who behave dishonestly for themselves are more likely to become leaders.

(b) Women's decision to become a leader is not driven by individual honesty preferences.

(c) Subjects who applied for leadership increase dishonesty for groups.

The regressions emphasized that the endogenous choice to apply for leadership apparently works as a sort of selection device for dishonest men. That is, they apply for leadership and again behave dishonestly when deciding in the group domain. By contrast, we do not support Hypothesis 3 for women.

When selection effects cannot explain women's behavior, the question remains: Why do women increase dishonesty when making decisions for groups? An explanation may be that

\footnotetext{
${ }^{10}$ Focusing on the control variables in Table 2, we find in model (2) that ambiguity preferences is positive and significant. In model (4), we find that risk tolerance and the econ dummy are significant and positive.
} 
women's honesty preferences could be context-dependent. More precisely, it is possible that women do not behave dishonestly for themselves but start to behave dishonestly when deciding for a group. Women's increase in dishonesty could result from an interaction effect of the deliberate decision to assume leadership and the payoff decision for the group. To disentangle the effect of the active application of assuming leadership and a mere preference change due to the context, we run a control treatment (exogenous leadership). This control treatment isolates subjects' active application as a leader from the pure responsibility of deciding on group payoffs.

\subsection{The Impact of Exogenous Leadership}

In the control treatment (exogenous leadership), subjects cannot apply for leadership. To isolate the effects of the decision to assume leadership, we compare the findings of the main treatment to the results in exogenous leadership. In this control treatment, we apply a similar sequence of actions as before. The only difference is that this treatment disables the leadership choice and leadership is exogenously determined by a random draw with varying probabilities $(1 / 3$ or $1 / 2$ ). Before the analysis, we check whether dishonest behavior for groups depends on the probability of becoming a leader. The data show that the probability ( $1 / 3$ vs. 1/2) does not significantly influence the fraction of dishonest reports in the groups (Fisher's exact test, $p=0.323$ ) and increased misreporting when deciding for groups (a dummy, which is positive when subjects misreported for groups, but not for themselves) (Fisher's exact test, $p=0.439) .{ }^{11}$ We also run two Probit regressions which confirm the non-parametric test results and show that the probability of becoming a leader has no effect $(p>0.532) .{ }^{12}$ Thus, we merge these data.

Figure 3 presents the share of profitable dishonest behavior for individual payoffs and group payoffs when leadership is exogenously determined.

Again, we find a gender difference in dishonest behavior when subjects decide for themselves. That is, men behave significantly more often dishonestly (36\%) than women (12\%) (Fisher's exact test, $p=0.003)$. Focusing on group payoffs, we find a moderate but insignificant increase for men (from $36 \%$ to $46 \%$ ) (Wilcoxon matched-pairs test, $p=0.263$ ). In contrast to the endogenous treatment, women show a less pronounced and insignificant increase of dishonest behavior from the individual (12\%) to the group domain (18\%) (Wilcoxon matched-pairs test, $p=0.453$ ). As a consequence, the gender difference in dishonest behavior does not disappear for group decisions in the treatment when leaders are exogenously determined (Fisher's exact test, $p=0.001$ ). ${ }^{13}$

\footnotetext{
${ }^{11}$ In the endogenous treatment, we did a similar analysis and find that subjects' beliefs of becoming a leader do not significantly affect dishonest behavior for groups (Fisher's exact test, $p=0.463$ ), or the dishonest behavior for groups $(p=0.223)$.

${ }^{12}$ In the two regressions, we included a dummy controlling for the two probabilities of ending up as a leader. We also included a gender dummy and the same controls as in tables 1 and 2. When we exclude these controls, the regressions yield similar results (the probability of becoming a leader has no effect: $p>0.309$ ).

${ }^{13}$ In the endogenous treatment, subjects stated the probability of ending up as a leader. A possible explanation for the treatment effect could be that this probability distribution is significantly different from the communicated probability distribution of becoming a leader in the exogenous treatment. However, we do not find a statistical significant difference across treatments (Fisher's exact test, $p=0.206$ ).
} 


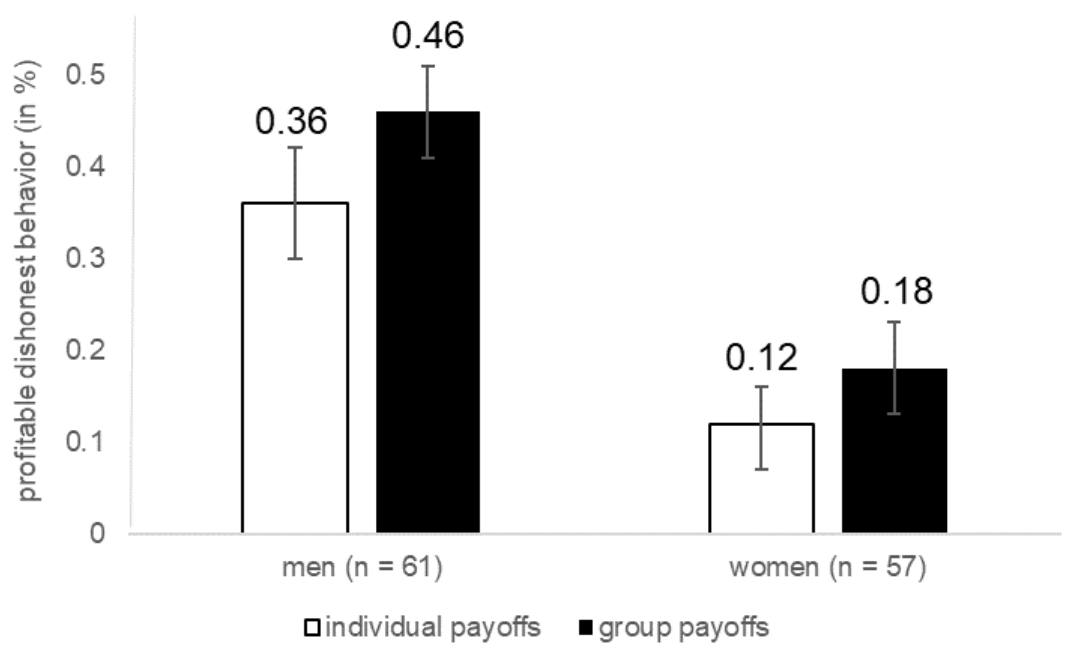

Figure 3: Percentage of profitable dishonest reports in exogenous leadership. White (black) bars present the reports for individual payoffs (group payoffs). Standard error bars included.

The finding that women do not increase dishonest behavior for groups without explicit application for leadership demonstrates that their dishonest behavior is not purely contextdependent. Probit regressions confirm this treatment difference in dishonest behavior for groups.

The regressions in Table 3 compare women's increase in dishonest behavior in the endogenous treatment and the exogenous treatment. For this, we apply subsample regressions. Models (1)(2) compare the increase in dishonest behavior of women who wanted to be leaders in endogenous leadership with all women in the exogenous treatment. That is, the models focus on a dummy, which becomes positive when subjects increased dishonest behavior in the group domain, as compared to reporting for themselves Models (3)-(4) compare the increase in dishonest behavior of women who opted against leadership in endogenous leadership with all women in the exogenous treatment. In all models, we identify women in the exogenous treatment with a dummy variable (exogenous leadership), which becomes positive in the exogenous treatment.

In models (2) and (4), we include the same control variables as in the previous regressions. We also add a control variable that accounts for subjects' beliefs (belief of becoming leader) that they will end up as a leader in the two treatments. To compute the (perceived) probability in the endogenous treatment, we used subjects' guesses on how many other subjects want to become a leader. In the exogenous treatment, the variable is the communicated probability of ending up as a leader. All regressions report average marginal effects (see Table 7 in Appendix A for the corresponding Probit model).

In models (1)-(2), the negative significant coefficient of exogenous leadership demonstrates that women who could not apply for leadership increase dishonest behavior less often than women who actively applied for leadership in the endogenous treatment. We do not find treatment differences when we compare women who did not apply for leadership in the endogenous 
Table 3: Probit regressions on women's increase in dishonesty for groups (endo. vs. exo).

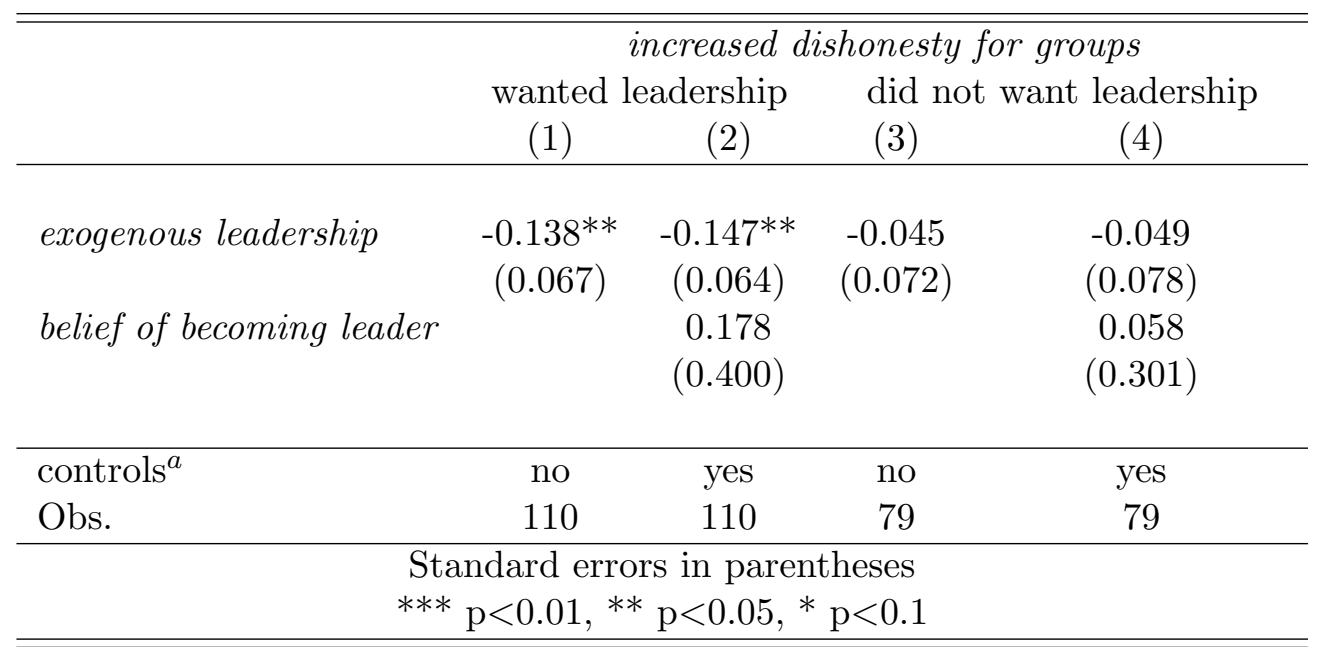

Note: The regressions report average marginal effects.

${ }^{a}$ Controls: Risk preferences, competition preferences, fairness, ambiguity preferences, age, and whether subjects study economics.

treatment and women in the exogenous condition. That is, in model (3) exogenous leadership is insignificant and model (4) shows that the results are robust to the inclusion of subjects' beliefs and controls. ${ }^{14}$ Thus, the treatment difference of leadership behavior is not driven by differences in beliefs. We ran the same regression models for male subjects and find no significant treatment effect in any of the four models (see Table 9 in Appendix A).

\section{Result 3: Dishonest Behavior under Exogenous Leadership}

(a) Under exogenous leadership, women behave less dishonestly for groups than men.

(b) Under exogenous leadership, women behave less dishonestly for groups than women who actively wanted to assume leadership in the endogenous treatment.

So far, the results show that selection effects cannot explain the increase in women's misreporting behavior for groups. Furthermore, we rule out that women's honesty preferences are solely context-dependent, i.e., whether they have to decide for individual or group payoffs. We demonstrated that as soon as we disable the choice option to become a leader, women do not behave more dishonestly in the group than in the individual domain. Hence, we conclude that the treatment difference in the increase of dishonesty for groups is related to the leader-choice option. More precisely, it is possible that the active choice to assume leadership interacts with the decision to report the payoffs of a group. We speculate that the decision to assume leadership may lead to a behavioral change for female leaders who then try to align their behavior to

\footnotetext{
${ }^{14}$ We find that risk tolerance is significantly positive, i.e., with increasing risk tolerance, women become more likely to increase misreporting behavior for groups.
} 
the honesty preferences of their group members. In this respect, it is interesting to see whether female leaders' dishonest behavior coincides with their beliefs on group members' honesty preferences. We conduct a follow-up experiment (study 2) to learn more about the behavioral change in dishonest behavior and the hypothesized mechanisms on the role of women's beliefs.

\section{Study 2: Channels of Dishonest Behavior}

In this section, we report the results of our follow-up study. In this study, we focus on the endogenous treatment to get a better understanding of the interaction effect of women's willingness to assume leadership and their decisions when reporting group payoffs. We investigate two potential channels. First, the active choice to decide on behalf of the group may activate an increased sense of responsibility. Assuming responsibility for the group may heighten female leaders' focus on the other group members' preferences. Thus, female leaders may try to behave in line with the individual honesty preferences of other group members.

To examine this mechanism, we measure women's beliefs on the reporting decision of a randomly selected group member concerning his/her individual payoffs. Furthermore, we measure women's beliefs on the dishonest behavior of other group members when deciding on the group payoffs. These beliefs may vary depending on the gender composition of the group. If female leaders believe that men are more dishonest and these beliefs influence their dishonest behavior in groups, they should behave more dishonestly in male groups. Therefore, we take the different gender compositions of each group into account. Second, since the decisions of female leaders impact the payoffs of other group members, womens' social value orientation (SVO) may affect the misreporting behavior for groups. Prosocial women in particular, in contrast to women who are more concerned with their individual payoff, may increase dishonest behavior for the group. Therefore, we elicit subjects' SVO. We also conduct a post-experimental questionnaire to learn more about subjects' motives for behaving dishonestly for the group.

\subsection{Study 2: Experimental Design}

The experiment is almost identical to the first study. ${ }^{15}$ It comprises seven parts and one of them is randomly determined to be payoff-relevant. In the first block of the experiment, we measure subjects' preferences. That is, we elicit risk preferences with the method of Eckel and Grossman (2002) and social value orientation with the ring measure of Liebrand and McClintock (1988). Here, subjects are repeatedly confronted with two possible payoff allocations between themselves and another subject. In each decision set, the allocations vary in payoff differences. Subjects have

\footnotetext{
${ }^{15}$ The second study is not a replication study. Instead, we aim to dig deeper into the mechanisms of women's behavior change under endogenous leadership. For this, we elicit leaders' beliefs on the dishonest behavior of the group members social value orientation (SVO). Since we had time constraints in the experiment, we had to drop the elicitation of the Fehr and Schmidt (1999) parameters and ambiguity attitudes since the study would have become too long.
} 
to decide for one payoff allocation and trade off between more money for themselves and more equal/more money in total for both. Based on their choices, one can calculate an angle value for each subject (see Appendix B for details). Afterward, we measure competitive preferences (Niederle and Vesterlund, 2007). Next, we measure individual honesty preferences.

In a next part, we measure dishonest behavior for groups. Here, a slight difference occurs and we intentionally vary the groups' gender compositions. We create groups with three women, a woman and two men, and with two women and one man. We use a special algorithm that aims to generate mainly these compositions. With excessive men in the session, the algorithm forms groups consisting only of men. In this part, everything is equal to the previous experiment. However, additionally, we inform subjects on the gender, age, and semester number of the other subjects. ${ }^{16}$ Subjects receive this information after making their leader-choice decisions and before making their group reporting decision. We apply this timing to rule out that the decision to become a leader is affected by the information on the gender composition in the group.

Next, we elicit subjects' beliefs on dishonesty in groups, i.e., their beliefs about the reporting decision for the case when other group members reported the payoffs of the group. Therefore, subjects learn that the computer randomly rolls a die for the whole group. After subjects see the die-roll, they make their reporting decision. Thereafter, we elicit their beliefs on other group members' reporting decisions. For this, we again show the subjects some information (gender, age, and semester number) on the other two group members. They have to guess which number each of the two group members reported. Subjects receive $€ 1$ for each correct guess, reducing the likelihood of motivated beliefs.

In a next step, we elicit women's beliefs on individual dishonesty, i.e., their belief about other group members' individual reporting decisions. To measure this, we ask subjects about the reporting decision of a randomly selected group member. For this, we show them the information of the selected group member. Then, subjects have to state the reported number for each possible die number between one and six. ${ }^{17}$ Finally, we ask subjects questions on their motives for becoming/or not becoming a leader. We also ask them about the motives for the report they made. The study design of study 2 is illustrated in Figure 4 . We highlighted the changes in black whereas the initial study design is illustrated in gray.

In the follow-up study 219 subjects (90 male; 129 female) participated. We only invited subjects who did not participate in study one. On average, the sessions lasted 70 minutes and subjects earned $€ 12.64$.

\footnotetext{
${ }^{16}$ We elicit this information at the very beginning of the experiment. Here, subjects are told that it is possible that this information may be communicated to other subjects in the course of the experiment. We do not present this information in the male-only treatment since we intended to use this treatment as control data.

${ }^{17}$ We apply the strategy method to elicit their beliefs. Subjects are told that the computer checks for the real die number, which was shown to the matched person in part six. The computer refers to their belief for this number and checks whether it coincides with the reported number. If their belief was correct they earned $€ 1$.
} 


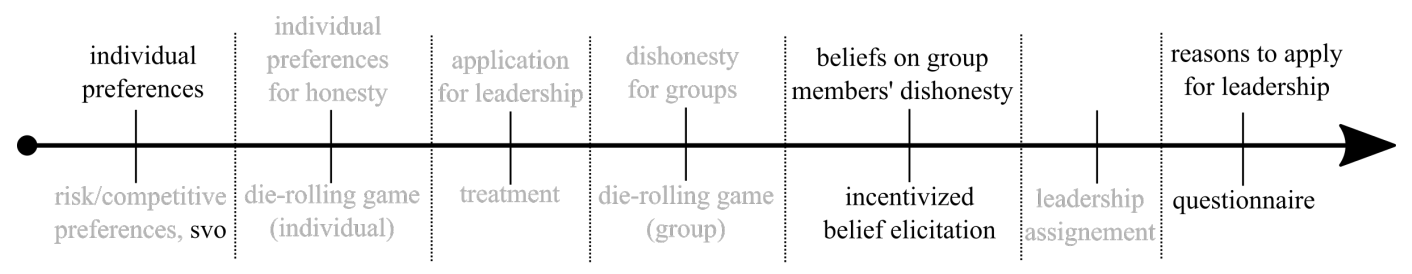

Figure 4: Experimental sequence of study two; in black the additional elements to study 1

\section{$5.2 \quad$ Study 2: Results}

The aggregate data of study two confirm our previous findings of the first study. Women significantly increase dishonest behavior from $12 \%$ to $23 \%$ when deciding on the group payoffs (Wilcoxon matched-pairs test, $p=0.004$ ). Turning to men, we find that the increase is less pronounced (from $13 \%$ to $21 \%$ ) and fails significance (Wilcoxon matched-pairs test, $p=0.108$ ). In further analyses, we focus on women's decisions since the purpose of study two is to learn more about women's behavioral change when they assume leadership.

To start with, we analyze the impact of group compositions on reporting decisions. We find that female leaders' dishonest behavior does not differ between all possible group compositions (only women, one men, two men) (Fisher's exact test on joint data, $p=0.531$ ). The same holds when focusing on women's increase of dishonest behavior for groups (Fisher's exact test on joint data, $p=0.755)$. Thus, we merge these data for further analyses.

\subsubsection{The Impact of Beliefs and Social-Value Orientation}

In this section, we explore whether women's reporting decisions for the group are influenced by their beliefs about the individual honesty preferences of other group members. We start this analysis by focusing on the effects of the leadership choice on dishonest behavior. The data support our previous findings, i.e., women who apply for leadership behave significantly more dishonestly $(24 \%)$ in the group compared to the individual domain $(11 \%)$ (Wilcoxon matchedpairs test, $p=0.005) .{ }^{18}$

Next, we turn to the first potential channel of the increased misreporting in groups. We focus on women's belief on individual dishonesty, i.e., their belief about other group members' individual reporting decisions. We use the measure of individual honesty preferences since it may be more informative as beliefs on dishonesty in groups may also reflect the decision-makers' beliefs about other group members' social preferences. We find that subjects' belief that group members misreport, i.e., the average belief is higher than the real die number. The only exception is die number five with an average belief of 4.46, which is slightly below five. Based on the beliefs for all possible die numbers, we calculate the mean-belief as an aggregate measure of the believed (dis-)honesty of the other group members.

\footnotetext{
${ }^{18}$ Focusing on men who wanted to become a leader, we also support the previous findings. That is, the impact of endogenous leadership is less pronounced, i.e., men show an insignificant increase of dishonest behavior from $13 \%$ to $22 \%$ (Wilcoxon matched-pairs test, $p=0.180$ ).
} 
Figure 5 overviews women's increase in dishonest behavior between the individual and the group domain.

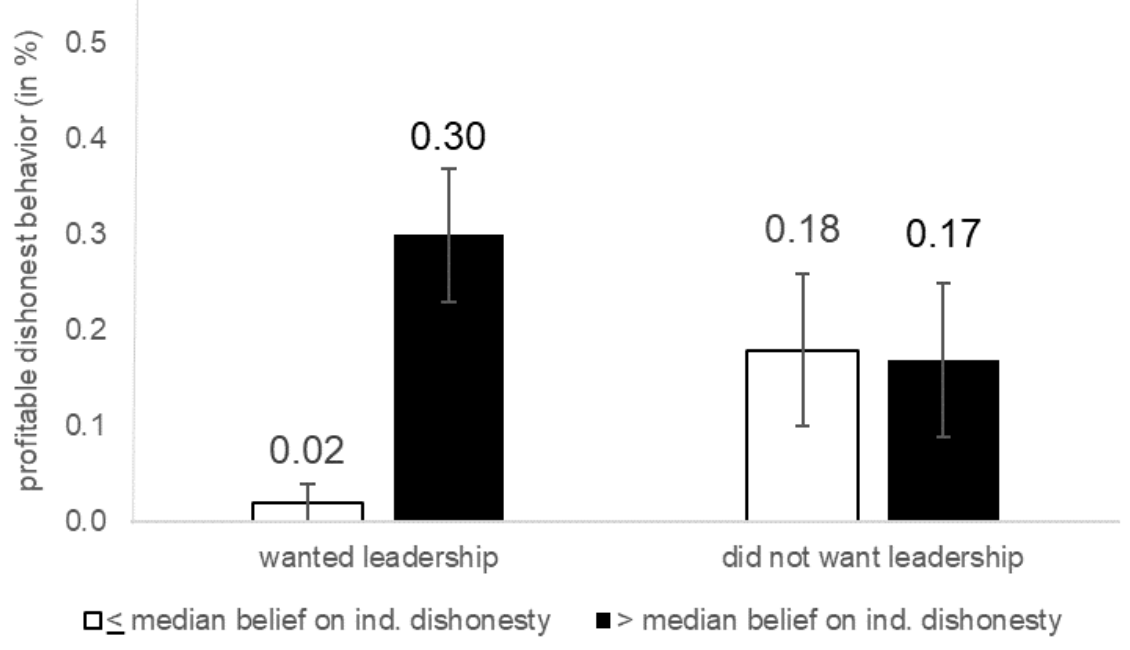

Figure 5: Women's increase in dishonesty when deciding on group payoffs, conditional on leader choice and on their belief on individual dishonesty. Standard error bars included.

It distinguishes between women who wanted to become a leader (left panel) or not (right panel). The figure also differentiates on women's belief on individual dishonesty and presents the effects conditional on the median split (3.0). We distinguish between a below/equal-median belief (white bars) and an above-median belief (black bars).

The diagram shows that women who wanted to assume leadership align their dishonest behavior for groups based on their belief of individual dishonesty. When these women have an above-median belief on the individual misreporting behavior of the other group members, they show a substantially higher increase $(30 \%)$ in dishonesty, as compared to women who hold a low belief $(2 \%)$ (Fisher's exact test, $p<0.001)$. Turning to women who did not want to assume leadership, we do not find such a pattern. In this case, misreporting behavior is independent of the beliefs and women who hold a below-median belief show a similar increase (18\%) in dishonest behavior to women who hold an above-median belief (17\%) (Fisher's exact test, $p=1.000$ ).

Regarding our second channel of the increased misreporting in groups, we apply Probit regression analyses, controlling for the impact of social value orientation. In model (1), we use the full sample of female decisions, unconditional on the willingness to assume leadership. Model (2) focuses on the subsample of women who wanted to assume leadership whereas model (3) concentrates on the subsample of women who did not want to assume leadership.

We always control for women's belief on individual dishonesty. The models also include svo, which is the angle value of subjects' social value orientation. In models (2) and (3), we also include control variables, i.e., subjects' risk preferences, competition preferences, age, and whether they study economics. All models are clustered on subjects' matching groups of the commu- 
Table 4: Probit regressions on the increase in dishonesty of women conditional on their leadership preferences.

\begin{tabular}{lccc}
\hline \hline & \multicolumn{3}{c}{ increase in dishonest behavior } \\
& all data & wanted leadership & did not want leadership \\
& $(1)$ & $(2)$ & $(3)$ \\
\hline \multirow{3}{*}{ belief on individual dishonesty } & $0.107^{* * *}$ & $0.140^{* * *}$ & 0.027 \\
svo & $(0.028)$ & $(0.028)$ & $(0.071)$ \\
& $0.001^{* *}$ & 0.001 & $0.004^{* *}$ \\
& $(0.001)$ & $(0.001)$ & $(0.002)$ \\
\hline controls $^{a}$ & no & yes & yes \\
Obs. & 129 & 78 & 42 \\
\hline & Standard errors in parentheses & \\
\hline \hline
\end{tabular}

Note: The regressions are clustered at the group level and report average marginal effects.

${ }^{a}$ Controls: risk preferences, age, and whether subjects study economics.

nicated demographics of group members. The regressions report average marginal effects (see Table 10 in Appendix A for the corresponding Probit model). ${ }^{19}$

The regressions confirm the findings of Figure 3. That is, in model (1), the highly significant positive coefficient of belief on individual dishonesty demonstrates that the likelihood of dishonest behavior significantly increases in women's beliefs on group members' individual misreporting behavior. One may argue that this relation could be a consequence of "motivated beliefs." However, we do not believe that this should affect results, as we incentivized the belief elicitation. Thus, stating motivated beliefs would result in lower payoffs.

Moreover, the regression highlights that svo is significant and positive, which is in line with the idea that prosocial female leaders behave dishonestly to support group members. Model (2) emphasizes that the effect of women's belief on dishonesty is only relevant for women who wanted to assume leadership. We find that the coefficient of belief on individual dishonesty is positive and highly significant, whereas it becomes insignificant as soon as we concentrate on women who did not want to assume leadership (model (3)). Turning to svo, we find that prosociality is of importance for women who did not want to assume leadership. Here, more prosocial women are more likely to increase dishonesty for groups. Robustness checks show that the regression results hold when we apply women's beliefs on dishonesty in groups instead of the beliefs on individual dishonesty (see Table 11 in Appendix A).

\section{Result 4: Beliefs on Individual Dishonesty and Dishonesty in Groups}

(a) Women who want to assume leadership misreport significantly more for groups when they believe that group members have preferences for dishonesty.

\footnotetext{
${ }^{19}$ The sample size becomes smaller when we include control variables (models $\left.(1)-(2)\right)$. Due to a technical problem in the experiment we lost data on the risk preferences for nine subjects.
} 
(b) Women who did not want to assume leadership misreport significantly more for groups with increasing social value orientation (svo).

\subsubsection{Questionnaire}

In the questionnaire, we asked for the reasons to apply for leadership and to report specific payoffs. Subjects answered in free-form texts. We classified women's answers based on certain dimensions: (i) importance of active role in group decision; (ii) acting as a leader is more interesting; (iii) enforcement of individual honesty preferences; (iv) assuming responsibility for the group. Among women who applied for leadership, we find two large groups, which we report henceforth. First, $30.9 \%$ state that they wanted to have an active role, where they could influence the reporting decision. Second, $29.8 \%$ argue that they wanted to become leaders to assume responsibility for the group. A closer look shows that this share increases to $45 \%$ when focusing on women with a high belief in individual dishonesty. Moreover, $56 \%$ of them misreport for the group.

This pattern is supported when we focus on women's reasons for their reporting behavior. Women who have a high belief in individual dishonesty state in $23 \%$ of cases that they misreported to achieve a high payoff for group members. In contrast, for female leaders with a low belief in individual dishonesty, we find that this share is significantly smaller (4.4\%) (Fisher's exact test, $p=0.022)$. Hence, the questionnaire supports the idea that women who applied for leadership are shaped by a norm to fulfill the needs of group members.

Finally, when we focus on women who did not want to become leaders, we find that the majority (67.5\%) argue that they do not want to assume responsibility for the group.

\section{Conclusion}

In this paper, we analyzed in two studies gender differences in leadership decisions and dishonest behavior for groups. In the first study, we focused on a within-subjects experiment with two stages, where subjects first decide for themselves and subsequently report payoffs for their groups. Moreover, we model subjects' deliberate decision to apply for leadership. We can analyze whether this decision is related to individual honesty preferences and whether it impacts reporting behavior in a group context. Our second study focused on the mechanisms of women's dishonest behavior in the group domain.

Study one demonstrates that men behave more dishonestly than women in the individual domain, corroborating the predominant evidence. A novel finding of this study is that women alter their behavior when they act as leaders and wanted to assume leadership whereas men act similarly in the individual and in the group domain. A closer look at the leader-choice option reveals that men's decision to become a leader is shaped by their individual honesty preferences. 
By contrast, although women behave more dishonestly for groups, we do not find that their decision to apply for leadership is linked to their honesty preferences. Our control treatment disables the leader-choice option and highlights that, in this case, women's decision to behave dishonestly is not context-dependent, i.e., does not differ across the individual and the group context. The control treatment highlights that women do not increase dishonesty when they take up leadership positions per se. Our results suggest that women's explicit decision to assume responsibility for a group leads to a behavioral change.

The results of study two disclose a potential channel for female leaders' increase of dishonesty. That is, the explicit decision to become a leader motivates them to adjust their behavior to the honesty preferences of group members. This phenomenon does not depend on the group context per se. It occurs as a combination of the decision to become a leader who subsequently has to report payoffs for a group. We find that social value orientation only matters for women who did not want to assume leadership. That is, prosocial leaders are more likely to misreport when deciding for groups.

Our paper improves the understanding of women's and men's motivation to apply for leadership. We also shed light on gender differences in dishonest behavior when deciding for groups. We showed that women's decision to apply for leadership is not correlated to their honesty preferences. This highlights that the gender gap in the application to leadership positions may not be associated with women's less pronounced preference for dishonesty. This may imply that there is no need to address differing honesty preferences of men and women in workplace policies. Interestingly, we show that although women may not behave dishonestly for themselves, actively assuming responsibility motivates them to behave dishonestly for others. This highlights the importance of promotion mechanisms, as our results demonstrate that the opportunity to apply for leadership may lead to a behavioral change for women who decide for a group. This insight may imply that leadership demands that women implicitly change their preferences due to others' expectations. This may have a range of consequences. For instance, it suggests that affirmative action policies in the form of women's quota may not per se result in higher ethical standards at the management level. Moreover, if female executives have to adapt a leadership style that is not in line with individual preferences results in higher perceived mental stress (Gardiner and Tiggemann, 1999). It could result in women giving up the leadership position in the long term to reduce this mental stress. There is scarce experimental evidence on how employee's individual behavior changes when their role transforms from employee to leader. Our study is novel in this regard, observing individual changes in dishonesty behavior, and may spur further research in the future.

\section{References}

J. Abeler, D. Nosenzo, and C. Raymond. Preferences for truth-telling. Econometrica, 87(4):1115-1153, 2019. 
S. Alan and S. Ertac. Mitigating the gender gap in the willingness to compete: Evidence from a randomized field experiment. Journal of the European Economic Association, 17(4):1147-1185, 2019.

S. Alan, S. Ertac, E. Kubilay, and G. Loranth. Understanding gender differences in leadership. Economic Journal, 130(626):263-289, 2020.

A. Alesina, P. Giuliano, and N. Nunn. On the origins of gender roles: Women and the plough. Quarterly Journal of Economics, 128(2):469-530, 2013.

J. Andreoni and L. Vesterlund. Which is the fair sex? Gender differences in altruism. Quarterly Journal of Economics, 1(116):293-312, 2001.

O. H. Azar, S. Yosef, and M. Bar-Eli. Do customers return excessive change in a restaurant?: A field experiment on dishonesty. Journal of Economic Behavior $\& 3$ Organization, 93:219-226, 2013.

O. Bandiera, A. Prat, S. Hansen, and R. Sadun. CEO behavior and firm performance. Journal of Political Economy, 128(4):1325-1369, 2020.

B. M. Barber and T. Odean. Boys will be boys: Gender, overconfidence, and common stock investment. Quarterly Journal of Economics, 116(1):261-292, 2001.

S. L. Berman, A. C. Wicks, S. Kotha, and T. M. Jones. Does stakeholder orientation matter? The relationship between stakeholder management models and firm financial performance. Academy of Management Journal, 42(5):488-506, 1999.

M. Blanco, D. Engelmann, and H. T. Normann. A within-subject analysis of other-regarding preferences. Games and Economic Behavior, 72(2):321-338, 2011.

I. Bohnet, A. Van Geen, and M. Bazerman. When performance trumps gender bias: Joint vs. separate evaluation. Management Science, 62(5):1225-1234, 2016.

N. P. Bollen and V. K. Pool. Do hedge fund managers misreport returns? Evidence from the pooled distribution. Journal of Finance, 64(5):2257-2288, 2009.

A. Boring. Gender biases in student evaluations of teaching. Journal of Public Economics, 145:27-41, 2017.

P. Brañas-Garza, V. Capraro, and E. Rascon-Ramirez. Gender differences in altruism on mechanical turk: Expectations and actual behaviour. Economics Letters, 170:19-23, 2018.

A. Bucciol, F. Landini, and M. Piovesan. Unethical behavior in the field: Demographic characteristics and beliefs of the cheater. Journal of Economic Behavior \& Organization, 93:248-257, 2013.

N. Burns and S. Kedia. The impact of performance-based compensation on misreporting. Journal of Financial Economics, 79(1):35-67, 2006.

D. Card, S. DellaVigna, P. Funk, and N. Iriberri. Are referees and editors in economics gender neutral? Quarterly Journal of Economics, 135(1):269-327, 2020.

B. K. Church, R. L. Hannan, and X. J. Kuang. Shared interest and honesty in budget reporting. Accounting, Organizations and Society, 37(3):155-167, 2012. 
J. Conrads, B. Irlenbusch, R. M. Rilke, A. Schielke, and G. Walkowitz. Honesty in tournaments. Economics Letters, 123(1):90-93, 2014.

R. Croson and U. Gneezy. Gender differences in preferences. Journal of Economic literature, 47(2): 448-74, 2009.

Z. Dai, F. Galeotti, and M. C. Villeval. Cheating in the lab predicts fraud in the field: An experiment in public transportation. Management Science, 64(3):1081-1100, 2018.

A. Dreber and M. Johannesson. Gender differences in deception. Economics Letters, 99(1):197-199, 2008.

C. C. Eckel and P. J. Grossman. Are women less selfish than men?: Evidence from dictator experiments. Economic Journal, 108(448):726-735, 1998.

C. C. Eckel and P. J. Grossman. Sex differences and statistical stereotyping in attitudes toward financial risk. Evolution and Human Behavior, 23(4):281-295, 2002.

S. Ertac and M. Y. Gurdal. Deciding to decide: Gender, leadership and risk-taking in groups. Journal of Economic Behavior \& Organization, 83(1):24-30, 2012.

E. Fehr and K. M. Schmidt. A theory of fairness, competition, and cooperation. Quarterly Journal of Economics, 114(3):817-868, 1999.

U. Fischbacher. z-tree: Zurich toolbox for ready-made economic experiments. Experimental Economics, 10(2):171-178, 2007.

U. Fischbacher and F. Föllmi-Heusi. Lies in disguise - an experimental study on cheating. Journal of the European Economic Association, 11(3):525-547, 2013.

L. Flabbi, M. Macis, A. Moro, and F. Schivardi. Do female executives make a difference? The impact of female leadership on gender gaps and firm performance. Economic Journal, 129(622):2390-2423, 2019.

M. Gardiner and M. Tiggemann. Gender differences in leadership style, job stress and mental health in male-and female-dominated industries. Journal of Occupational and Organizational Psychology, 72(3): 301-315, 1999.

F. Gino, S. Ayal, and D. Ariely. Self-serving altruism? The lure of unethical actions that benefit others. Journal of Economic Behavior \&3 Organization, 93:285-292, 2013.

U. Gneezy, A. Imas, and J. List. Estimating individual ambiguity aversion: A simple approach. Technical report, National Bureau of Economic Research, 2015.

B. Greiner. Subject pool recruitment procedures: Organizing experiments with ORSEE. Journal of the Economic Science Association, 1(1):114-125, 2015.

K. Grosch and H. A. Rau. Gender differences in honesty: The role of social value orientation. Journal of Economic Psychology, 62:258-267, 2017.

K. Grosch, S. Müller, H. Rau, and L. Zhurakhovska. Simplifying the elicitation of preferences: A lab-inthe-field approach in Kenya. Mimeo, 2020. 
P. J. Grossman, C. Eckel, M. Komai, and W. Zhan. It pays to be a man: Rewards for leaders in a coordination game. Journal of Economic Behavior \& Organization, 161:197-215, 2019.

S. D. Haigner and F. Wakolbinger. To lead or not to lead: Endogenous sequencing in public goods games. Economics Letters, 108(1):93-95, 2010.

R. Hanna and S.-Y. Wang. Dishonesty and selection into public service: Evidence from India. American Economic Journal: Economic Policy, 9(3):262-90, 2017.

M. E. Heilman and J. J. Chen. Same behavior, different consequences: Reactions to men's and women's altruistic citizenship behavior. Journal of Applied Psychology, 90(3):431, 2005.

D. Houser, S. Vetter, and J. Winter. Fairness and cheating. European Economic Review, 56(8):1645-1655, 2012.

D. Joulfaian. Corporate income tax evasion and managerial preferences. Review of Economics and Statistics, 82(4):698-701, 2000.

A. Kajackaite and U. Gneezy. Incentives and cheating. Games and Economic Behavior, 102:433-444, 2017.

M. G. Kocher, S. Schudy, and L. Spantig. I lie? We lie! Why? Experimental evidence on a dishonesty shift in groups. Management Science, 64(9):3971-4470, 2017.

M. Kosfeld, A. Okada, and A. Riedl. Institution formation in public goods games. American Economic Review, 99(4):1335-55, 2009.

W. B. Liebrand and C. G. McClintock. The ring measure of social values: A computerized procedure for assessing individual differences in information processing and social value orientation. European Journal of Personality, 2(3):217-230, 1988.

N. M. Lorinkova, M. J. Pearsall, and H. P. Sims Jr. Examining the differential longitudinal performance of directive versus empowering leadership in teams. Academy of Management Journal, 56(2):573-596, 2013

F. Mengel, J. Sauermann, and U. Zölitz. Gender bias in teaching evaluations. Journal of the European Economic Association, 17(2):535-566, 2019.

M. Niederle and L. Vesterlund. Do women shy away from competition? Do men compete too much? Quarterly Journal of Economics, 122(3):1067-1101, 2007.

A. Özgümüs, H. A. Rau, S. T. Trautmann, and C. König-Kersting. Gender bias in the evaluation of teaching materials. Frontiers in Psychology, 11:1074, 2020.

S. J. Peterson, B. M. Galvin, and D. Lange. CEO servant leadership: Exploring executive characteristics and firm performance. Personnel Psychology, 65(3):565-596, 2012.

J. Potters and J. Stoop. Do cheaters in the lab also cheat in the field? European Economic Review, 87: 26-33, 2016. 
D. G. Rand, V. L. Brescoll, J. A. Everett, V. Capraro, and H. Barcelo. Social heuristics and social roles: Intuition favors altruism for women but not for men. Journal of Experimental Psychology: General, 145(4):389, 2016.

M. F. Rivas and M. Sutter. The benefits of voluntary leadership in experimental public goods games. Economics Letters, 112(2):176-178, 2011.

R. Selten. Die Strategiemethode zur Erforschung des eingeschränkt rationalen Verhaltens im Rahmen eines Oligopolexperiments. Sauermann, H.(Ed.), Beiträge Zur Experimentellen Wirtschaftsforschung, Mohr, Tübingen, 1967.

M. Sutter, S. Haigner, and M. G. Kocher. Choosing the carrot or the stick? Endogenous institutional choice in social dilemma situations. Review of Economic Studies, 77(4):1540-1566, 2010.

J. Zenger and J. Folkman. Women score higher than men in most leadership skill. Harvard Business Review, 2019. 


\section{Appendix A - Tables}

Table 5: Random effects Probit regressions on dishonest behavior in endogenous leadership.

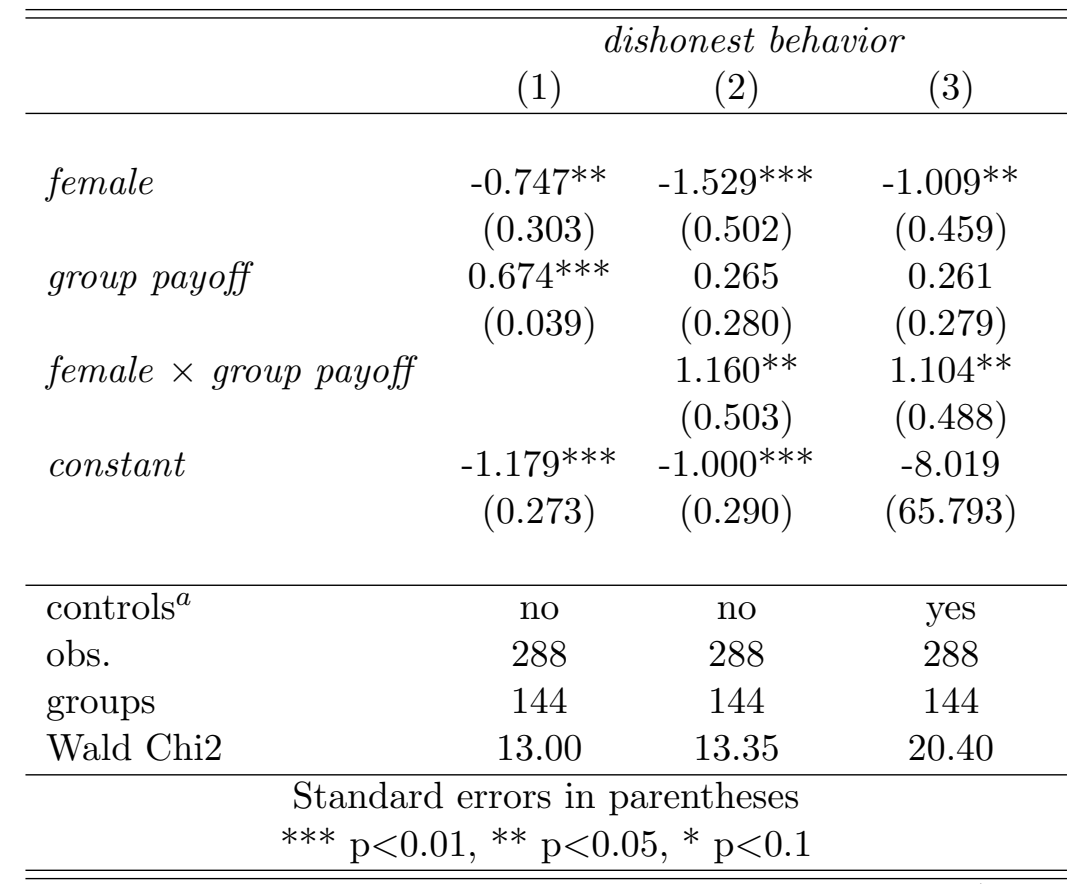

Note: The regressions are clustered on the subject level $(\mathrm{n}=$ 144).

${ }^{a}$ Controls: Risk preferences, competition preferences, fairness, ambiguity preferences, age, whether subjects study economics, and an order dummy. 
Table 6: Probit regressions on wanted leadership and dishonesty for groups (endog. leadership).

\begin{tabular}{|c|c|c|c|c|}
\hline & \multicolumn{2}{|c|}{ "wanted leadership } & \multicolumn{2}{|c|}{ dishonesty for groups } \\
\hline & $(1)$ & $(2)$ & $(3)$ & $(4)$ \\
\hline female & $\begin{array}{l}-0.185 \\
(0.238)\end{array}$ & $\begin{array}{l}-0.167 \\
(0.269)\end{array}$ & $\begin{array}{c}-0.189 \\
(0.227)\end{array}$ & $\begin{array}{c}0.163 \\
(0.265)\end{array}$ \\
\hline wanted leadership & & & $\begin{array}{c}0.607^{* *} \\
(0.290)\end{array}$ & $\begin{array}{c}0.630^{* *} \\
(0.305)\end{array}$ \\
\hline misreported for themselves & $\begin{array}{c}0.684^{*} \\
(0.405)\end{array}$ & $\begin{array}{c}1.153^{* *} \\
(0.574)\end{array}$ & & \\
\hline female $\times$ misreported for themselves & & $\begin{array}{l}-0.306 \\
(0.266)\end{array}$ & & \\
\hline constant & $\begin{array}{c}0.696^{* * *} \\
(0.187)\end{array}$ & $\begin{array}{c}-0.581 \\
(49.006)\end{array}$ & $\begin{array}{c}-0.973^{* * *} \\
(0.292)\end{array}$ & $\begin{array}{c}-2.484 \\
(54.782)\end{array}$ \\
\hline controls $^{a}$ & no & yes & no & yes \\
\hline obs. & 144 & 144 & 144 & 144 \\
\hline pseudo R2 & 0.030 & 0.098 & 0.034 & 0.116 \\
\hline $\begin{array}{l}\text { Standard } \\
* * * \quad \mathrm{p}<0.01\end{array}$ & $\begin{array}{l}\text { rs in } \mathrm{pe} \\
*^{2} \mathrm{p}<0.0\end{array}$ & $\begin{array}{l}\text { ntheses } \\
* \mathrm{p}<0.1\end{array}$ & & \\
\hline
\end{tabular}

${ }^{a}$ Controls: Risk preferences, competition preferences, fairness, ambiguity preferences, age, whether subjects study economics, and an order dummy. 
Table 7: Probit regressions on women's increase in dishonesty for groups (endo. vs. exo).

\begin{tabular}{|c|c|c|c|c|}
\hline & \multicolumn{4}{|c|}{ increased dishonesty for groups } \\
\hline & \multicolumn{2}{|c|}{ wanted leadership } & \multicolumn{2}{|c|}{ did not want leadership } \\
\hline exogenous leadership & $\begin{array}{c}-0.604^{* *} \\
(0.303)\end{array}$ & $\begin{array}{c}-0.778^{* *} \\
(0.348)\end{array}$ & $\begin{array}{l}-0.258 \\
(0.409)\end{array}$ & $\begin{array}{l}-0.311 \\
(0.494)\end{array}$ \\
\hline belief of becoming leader & & $\begin{array}{c}0.939 \\
(2.117)\end{array}$ & & $\begin{array}{c}0.365 \\
(1.905)\end{array}$ \\
\hline constant & $\begin{array}{l}-0.751 \\
(0.191)\end{array}$ & $\begin{array}{l}-120.444 \\
(116.842)\end{array}$ & $\begin{array}{l}-1.097 \\
(0.335)\end{array}$ & $\begin{array}{c}-57.755 \\
(120.115)\end{array}$ \\
\hline controls $^{a}$ & no & yes & no & yes \\
\hline obs. & 110 & 110 & 79 & 79 \\
\hline pseudo R2 & 0.044 & 0.199 & 0.008 & 0.114 \\
\hline $\begin{array}{r}\text { St: } \\
* * * \\
\end{array}$ & $\begin{array}{l}\text { dard erro } \\
<0.01 \text {, ** }\end{array}$ & $\begin{array}{l}\text { in paren } \\
0<0.05, *\end{array}$ & $\begin{array}{l}\text { eses } \\
<0.1 \\
\end{array}$ & \\
\hline
\end{tabular}

${ }^{a}$ Controls: Risk preferences, competition preferences, fairness, ambiguity preferences, age, and whether subjects study economics.

Table 8: Probit regressions on men's increase in dishonesty for groups (endo. vs. exo) Marginal effects reported.

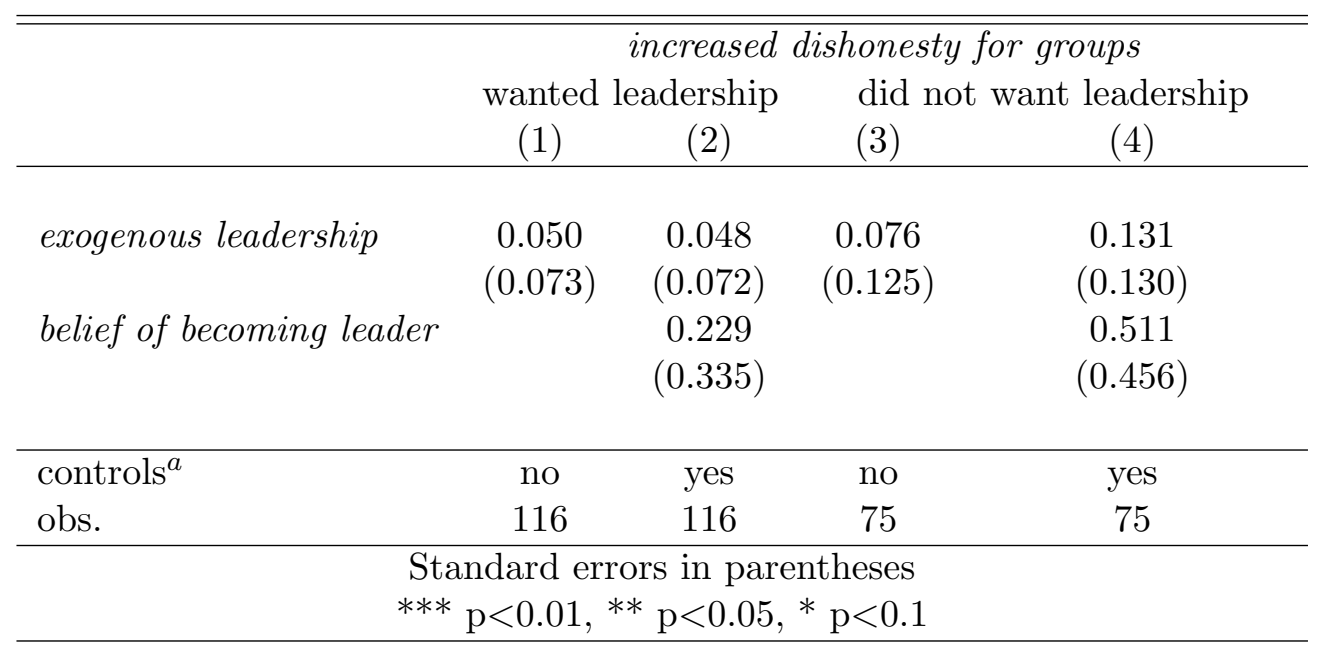

Note: The regressions report average marginal effects.

${ }^{a}$ Controls: Risk preferences, competition preferences, fairness, ambiguity preferences, age, and whether subjects study economics. 
Table 9: Probit regressions on men's increase in dishonesty for groups (endo. vs. exo).

\begin{tabular}{|c|c|c|c|c|}
\hline & \multicolumn{4}{|c|}{ increased dishonesty for groups } \\
\hline & \multicolumn{2}{|c|}{ wanted leadership } & \multicolumn{2}{|c|}{ did not want leadership } \\
\hline & $(1)$ & $(2)$ & $(3)$ & (4) \\
\hline \multirow[t]{2}{*}{ exogenous leadership } & 0.184 & 0.193 & 0.272 & 0.495 \\
\hline & $(0.271)$ & $(0.293)$ & $(0.452)$ & $(0.497)$ \\
\hline \multirow{2}{*}{ belief of becoming leader } & & 0.923 & & 1.932 \\
\hline & & $(1.361)$ & & $(1.762)$ \\
\hline \multirow[t]{2}{*}{ constant } & $-0.980 * * *$ & 35.478 & $-1.068^{* *}$ & 21.438 \\
\hline & $(0.202)$ & $(60.240)$ & $(0.414)$ & $(69.404)$ \\
\hline controls $^{a}$ & no & yes & no & yes \\
\hline obs. & 116 & 116 & 75 & 75 \\
\hline pseudo R2 & 0.004 & 0.079 & 0.005 & 0.051 \\
\hline \multicolumn{5}{|c|}{ Standard errors in parentheses } \\
\hline \multicolumn{5}{|c|}{$* * * \mathrm{p}<0.01, * * \mathrm{p}<0.05, * \mathrm{p}<0.1$} \\
\hline
\end{tabular}

${ }^{a}$ Controls: Risk preferences, competition preferences, fairness, ambiguity preferences, age, and whether subjects study economics.

Table 10: Probit regressions on the increase in dishonesty of women conditional on their leadership preferences. Marginal effects reported.

\begin{tabular}{lccc}
\hline \hline & \multicolumn{3}{c}{ increase in dishonest behavior } \\
& all data & wanted leadership & did not want leadership \\
& $(1)$ & $(2)$ & $(3)$ \\
\hline \multirow{3}{*}{ belief on individual dishonesty } & $0.510^{* * *}$ & $0.816^{* * *}$ & 0.124 \\
svo & $(0.147)$ & $(0.168)$ & $(0.341)$ \\
& $0.006^{* *}$ & 0.006 & $0.004^{* *}$ \\
constant & $(0.003)$ & $(0.007)$ & $(0.002)$ \\
& $-2.982^{* * *}$ & 68.545 & -116.162 \\
controls ${ }^{a}$ & $(0.591)$ & $(94.553)$ & $(218.99)$ \\
obs. & no & yes & 42 \\
pseudo R2 & 129 & 78 & 0.200 \\
\hline \multicolumn{5}{c}{0.146} & 0.302 & \\
\hline \hline
\end{tabular}

${ }^{a}$ Controls: risk preferences, age, and whether subjects study economics. 
Table 11: Probit regressions on the increase in dishonesty of women conditional on their leadership preferences.

\begin{tabular}{lccc}
\hline \hline & \multicolumn{3}{c}{ increase in dishonest behavior } \\
& all data & wanted leadership & did not want leadership \\
& $(1)$ & $(2)$ & $(3)$ \\
\hline \multirow{3}{*}{ belief on dishonesty in groups } & $0.227^{* * *}$ & $0.218^{* * *}$ & $0.333^{* * *}$ \\
svo & $(0.061)$ & $(0.072)$ & $(0.095)$ \\
& $0.001^{*}$ & 0.001 & $0.002^{* *}$ \\
& $(0.001)$ & $(0.001)$ & $(0.001)$ \\
\hline controls $^{a}$ & no & yes & yes \\
obs. $^{4}$ & 78 & 42 \\
\hline \hline
\end{tabular}

Note: The regressions report average marginal effects.

${ }^{a}$ Controls: risk preferences, age, and whether subjects study economics.

Table 12: Probit regressions on the increase in dishonesty of women conditional on their leadership preferences.

\begin{tabular}{lccc}
\hline \hline & \multicolumn{3}{c}{ increase in dishonest behavior } \\
& $(1)$ & $(2)$ & $(3)$ \\
\hline \multirow{2}{*}{ belief on dishonesty in groups } & $1.061^{* * *}$ & $1.013^{* * *}$ & $1.997^{* * *}$ \\
& $(0.313)$ & $(0.367)$ & $(0.721)$ \\
svo & $0.005^{*}$ & 0.003 & $0.014^{* *}$ \\
& $(0.003)$ & $(0.006)$ & $(0.007)$ \\
constant & $-1,622^{* * *}$ & 85.266 & 130.383 \\
& $(0.270)$ & $(85.094)$ & 240.020 \\
\hline controls ${ }^{a}$ & no & yes & 42 \\
obs. & 129 & 78 & 0.382 \\
pseudo R2 & 0.134 & 0.145 & \\
\hline \multicolumn{4}{c}{ Standard errors in parentheses } \\
& $* * *$ & $\mathrm{p}<0.01, * * \mathrm{p}<0.05, * \mathrm{p}<0.1$ & \\
\hline \hline
\end{tabular}

${ }^{a}$ Controls: risk preferences, age, and whether subjects study economics. 


\section{Appendix B - Preference elicitations (Study 1)}

\section{part one - elicitation of risk preferences}

In the risk elicitation task of Eckel and Grossman (2002), subjects had to choose one out of six lotteries. With a $50 \%$ probability each lottery leads to a low or a high payoff. Subjects' lottery choice can be interpreted as a measure of her degree of risk aversion, i.e., higher lottery numbers reflect riskier lotteries

\begin{tabular}{ccccc}
\hline \hline Choice & Low Payoff $(€)$ & High Payoff $(€)$ & Exp. payoff & Implied CRRA Range \\
\hline 1 & 5.60 & 5.60 & 5.60 & $3.46<r$ \\
2 & 7.20 & 4.80 & 6.00 & $1.16<r<3.45$ \\
3 & 8.80 & 4.00 & 6.40 & $0.71<r<1.16$ \\
4 & 10.40 & 3.20 & 6.80 & $0.50<r<0.71$ \\
5 & 12.00 & 2.40 & 7.20 & $0.00<r<0.50$ \\
6 & 14.00 & 0.40 & 7.20 & $r<0$ \\
\hline \hline
\end{tabular}

Table 13: Overview of the lottery choices in part 1. Risk is measured as standard deviation of expected payoff.

\section{part two - elicitation of advantageous inequality aversion}

In part two, the modified dictator game (MDG) of (Blanco et al., 2011) was used to measure subjects' aversion to advantageous inequality ( $\beta$ in Fehr and Schmidt, 1999). In the MDG, participants are presented to a list with 22 pairs of payoff vectors. They choose one of the two payoff vectors for all 22 pairs. Both vectors represent a money split between the dictator and the recipient. The left vector is constant and always $(20,0)$. If the participants choose it, they receive $€ 19$ and the recipients earn $€ 1$. All vectors on the right-hand side are increasing equal-money splits: from $(1,1)$ to $(21,21) .{ }^{20}$ The task aims to find out when subjects switch from $(20,0)$ to the equal split. The table contains 22 buttons, located above all decisions between an unequal and an equal split. Subjects know that clicking on a button has the effect that all equal splits below the button are marked for selection and all unequal splits above the button are also marked for selection. If a subject prefers all equal splits from $(3,3)$ to $(20,20)$ over the unequal split, she should click on the third button. Whereas, if a subject only prefers all equal splits starting from $(9,9)$ she should click on button 9 . The earlier a subject switches to the equal split, the more pronounced her aversion is to advantageous inequality.

\section{part three - elicitation of disadvantageous inequality aversion}

In part three we measured subjects' aversion to disadvantageous inequality ( $\alpha$ in Fehr and Schmidt, 1999) using the method of Blanco et al. (2011). In an ultimatum game using the strategy method (Selten, 1967) participants decide in the role of proposers and recipients. They know that after the experiment is finished, the computer will randomly pair two players and determine their role (proposer or recipient) and the payoff-relevant decision. At the beginning, all subjects decide as proposers. They have to decide how much of $€ 20$ they are willing to propose to the recipient. afterward, all subjects decide in the role of recipients. In this respect, they indicate which minimum proposer offer they would accept. Subjects are given a table with 22 rows of different proposals for each possible integer allocation

\footnotetext{
${ }^{20}$ Extending the right vectors to $(21,21)$ allows us to account for negative $\beta$ 's (Blanco et al., 2011).
} 
of the $€ 20$ between the two players. They have to indicate whether they would reject or accept each individual proposal. Therefore, all proposals have to be marked for rejection or acceptance. The goal is to find out, when subjects switch from rejecting an offer to accepting it. Therefore, the table contains 22 buttons which are located above each proposal. Subjects are told that clicking on a button would mean that all proposals below the button would be marked for acceptance, whereas all proposals above the button would be marked for rejection. For instance, if a subject wants to accept all proposals between 0 and 20 , she has to click on the first button. If she wants to accept all proposals starting from $€ 4$, she would click on button 4 . The higher the minimum accepted offer is, the higher a subject's aversion to disadvantageous inequality.

\section{part four, five, and six - elicitation of competitive preferences}

In parts four to six subjects participate in the mathematical real-effort task introduced by Niederle and Vesterlund (2007). Here, subjects have to add up five two-digit numbers. An example of the real-effort task (a math problem to be solved) is presented in Table 14. Subjects have to enter the answer in the blank box. Having submitting an answer, subjects are presented with the next problem without being informed of whether the answer was correct or not.

\begin{tabular}{|l|l|l|l|l|l|}
\hline 75 & 33 & 12 & 19 & 25 & \\
\hline
\end{tabular}

Table 14: Example of a problem in the real-effort task

In part four subjects work for five minutes in the real-effort task. We follow Niederle and Vesterlund (2007) and pay subjects a piece rate of $€ 0.50$ for each correctly solved problem. In part five subjects are matched in groups of four and participate in a tournament. They again spend five minutes completing the real-effort task. Here, their individual payments depend on their own performance compared to the performance of the three other participants in their group. If a subject achieves the best performance in the group, she receives $€ 2$ for each correct answer. However, if a subject does not achieve the best performance, she earns nothing. We measure subjects competitiveness preferences in part four, as their willingness to participate in a tournament. Therefore, subjects have to decide whether they want to participate in a tournament against three other participants, or whether they want to work under a piece rate. After subjects make their choices, they were given another five minutes to compete the real-effort task. If subjects work under the tournament, their performance is compared to the performance of the other three members of the group they are assigned to in part five (Niederle and Vesterlund, 2007).

\section{part seven - elicitation of ambiguity attitudes}

In this part subjects can earn Talers. We apply an exchange rate of 1 Taler $=€ 0.05$. To elicit individual ambiguity preferences, subjects decide in a multiple price list (MPL) design by Gneezy et al. (2015) with 20 rows. Each row involves a choice between a risky gamble in the left column (Option A) and an ambiguous gamble in the right column (Option B). Subjects are told that the payoffs of the options depend on the color which is drawn out of two urns that are filled with a certain number of red and black balls. They know that the risky urn (Option A) is exactly composed with 50 red and black balls. Whereas, they know that the composition of the ambiguous urn (Option B) is unknown. Before subjects are presented the choice list, they have to bet on a color (red or black). They are told that they receive the high payoff if this color will be drawn in the urn draw. After subjects make their bet, they have to 
decide for all 20 rows of the MPL, whether they prefer the risky lottery (Option A) or the ambiguous lottery (Option B). The possible payoff of Option A is constant for all 20 rows, i.e., when choosing Option A subjects always can win 200 Taler with a probability of $50 \%$. Whereas, the payoff of Option $\mathrm{B}$ is increasing when subjects go down by one row. It starts from 164 Talers (row 1) and ends at 316 Talers (row 20). Subjects receive these payoffs with a subjective probability of $50 \%^{21}$ The switch point determines subjects' ambiguity attitude. That is, subjects who switch early (late) from Option A to Option B are characterized by a lower (higher) degree of ambiguity preferences. Subjects know that if part five would become payoff relevant, a random draw would select one of the 20 rows. Subjects' choice in this row would be selected to be payoff relevant. If subjects have selected Option A, they are playing a random draw with a probability of $50 \%$. If however, Option B was selected, then subjects play the corresponding lottery. The composition of the ambiguous urn is randomly determined by a computer.

\section{Appendix B - Preference elicitations (Study 2)}

[The elicitation of risk preferences and competitive preferences was similar as in study 1.]

\section{part two - elicitation of social value orientation}

We elicit social value orientation with the ring measure of Liebrand and McClintock (1988). In this part subject are randomly matched with another participant and are subsequently presented to 32 pairs ("opportunity A" and "opportunity B") of allocation decisions between themselves and the matched person. In each of the 32 decision situations, subjects either have to choose opportunity A or B. In these cases subjects decide about points, which will be converted at an exchange rate of 1 point $=€ 0.02$, if the part becomes payoff relevant. For each pair, subjects have to trade off allocations, which differ in the degree of disadvantageous/advantageous inequality between the subject and the matched subject. At the same time, subjects are also matched with a different subject, who also allocates points to herself and the matched subject. Subjects know that if part two will become payoff relevant, they will earn the sum of the point, that they allocated to themselves plus the points, which were allocated to them by the second matching partner. If the part becomes payoff relevant, subjects are also informed on the total amount of points they received. Using subject's mean allocations for self and for the matched participant, shifting the base of the resulting angle to the center and taking the ratio between these means one can estimate the subject's motivational vector. This gives us the social value orientation angle of the subjects.

\footnotetext{
${ }^{21}$ Recall, that subjects bet on one of two colors.
} 